\title{
Effects of Maternal Hypoxia during Pregnancy on Bone Development in Offspring: A Guinea Pig Model
}

\author{
Alice M. C. Lee, ${ }^{1}$ Janna L. Morrison, ${ }^{1}$ Kimberley J. Botting, ${ }^{1,2}$ \\ Tetyana Shandala, ${ }^{1}$ and Cory J. Xian ${ }^{1}$ \\ ${ }^{1}$ Sansom Institute for Health Research, School of Pharmacy and Medical Sciences, University of South Australia, City East Campus, \\ GPO Box 2471, Adelaide, SA 5001, Australia \\ ${ }^{2}$ Discipline of Physiology, School of Medical Sciences, University of Adelaide, Adelaide, SA 5005, Australia
}

Correspondence should be addressed to Cory J. Xian; cory.xian@unisa.edu.au

Received 10 January 2014; Revised 9 April 2014; Accepted 10 April 2014; Published 14 May 2014

Academic Editor: Andreas Höflich

Copyright (C) 2014 Alice M. C. Lee et al. This is an open access article distributed under the Creative Commons Attribution License, which permits unrestricted use, distribution, and reproduction in any medium, provided the original work is properly cited.

\begin{abstract}
Low birth weight is associated with reduced bone mass and density in adult life. However, effects of maternal hypoxia (MH) on offspring bone development are not known. Objective. The current study investigated the effects of fetal growth restriction induced by $\mathrm{MH}$ during the last half of gestation on bone structure and volume in the offspring of the fetus near term and the pup in adolescence. Methods. During 35-62-day gestation (term, 69d), guinea pigs were housed in room air $\left(21 \% \mathrm{O}_{2}\right.$; control) or $12 \% \mathrm{O}_{2}$ $(\mathrm{MH})$. Offspring femur and tibia were collected at $62 \mathrm{~d}$ gestation and $120 \mathrm{~d}$ after birth. Results. MH decreased fetal birth weight but did not affect osteogenic potential pools in the fetal bone marrow. Histological analysis showed no effects of MH on tibial growth plate thickness in either fetal or postnatal offspring, although there was increased VEGF mRNA expression in the growth plate of postnatal offspring. MH did not change primary spongiosa height but lowered collagen-1 mRNA expression in postnatal offspring. There was increased mRNA expression of adipogenesis-related gene (FABP4) in bone from the MH postnatal offspring. Conclusion. MH during late gestation did not change the pool of osteogenic cells before birth or growth plate heights before and after birth. However, MH reduced expression of bone formation marker (collagen-1) and increased expression of fat formation marker (FABP4) in postnatal offspring bone.
\end{abstract}

\section{Introduction}

Body composition and musculoskeletal development begin in embryonic life, when bone and muscle develop from the mesodermal layer. Longitudinal bone growth before and after birth takes place in the growth plate located at the epiphyses of long bones via an endochondral ossification process in which a hypertrophic cartilage template is made, calcified, and invaded by blood vessels and then converted to trabecular bone through the action of bone forming cells, osteoblasts, and bone resorbing cells, osteoclasts [1]. Bone mass and bone size increase throughout childhood, reaching their peak at the end of adolescence, when growth plates are closed $[2,3]$. While optimal bone growth achieved during childhood is critical both for ensuring optimal development and protection from fractures during childhood, evidence is growing that peak bone mass is also an important contributor to bone mass and strength in later life [4]. Peak bone mass is a predictor of the age of onset of osteoporosis and a determinant of osteoporotic fracture risk in the elderly [5-8], a skeletal disorder associated with a progressive decrease in bone mineral density (BMD) and an increase in bone fragility and susceptibility to fractures.

There are a range of endocrine and paracrine factors that regulate bone growth [1]. Alterations to the diet of pregnant animals can produce lasting changes in the phenotype, physiology, and metabolism of the offspring [9-12]. This results in a range of adaptations that occur in response to the reduced substrate supply and have been shown to permanently program its physiology and metabolism [11, 13]. Fetal growth restriction can be caused by maternal undernutrition, maternal hypoxia $(\mathrm{MH})$, maternal smoking, and placental insufficiency [13, 14]. Placental insufficiency and $\mathrm{MH}$ both result in fetal hypoxemia during the latter part 
of pregnancy $[15,16]$. Studies have shown that birth weight is associated with bone mass, and low birth weight is related to a low bone mineral content in adults and increased fracture risks later in life [17-19]. However, the role of hypoxia on bone formation/remodelling is unclear.

In multicellular species, local oxygen partial pressure represents the functional regulator of oxygen homeostasis in the lung, blood, and other tissues. Insufficiency of oxygen can result in a failure to generate sufficient ATP to maintain essential cellular functions [18]. In physiological circumstance or pathological conditions, a program of gene expression changes is induced by hypoxia-inducible factor-1 (HIF-1). HIF-1 controls hypoxic expression of genes with metabolic functions such as glucose transport and metabolism and angiogenic factors like vascular endothelial growth factor (VEGF). As a subunit of HIF, HIF- $\alpha$ is a hypoxically responsive component. Studies have suggested that induced hypoxia in mouse and rabbit embryos leads to a variety of developmental defects that occur in places including the heart and vertebral column $[17,19,20]$. Furthermore, smoking during pregnancy, which causes fetal hypoxemia, may suppress bone matrix synthesis and mineralisation during gestation with lower osteocalcin levels in the umbilical blood in neonates of smoking mothers [20]. In vitro studies with human mesenchymal stem cells exposed to reduced oxygen tension demonstrated delayed osteoblast maturation, shown by reduced mRNA expression of osteocalcin and type 1 collagen (Cola1). However, it appears that the timing and the extent of the hypoxia influence the type of developmental process that is disrupted [21].

We hypothesised that $\mathrm{MH}$ would result in decreased bone development in the fetus and thus reduced bone mass in adolescence. The current study examined the effects of fetal growth restriction induced by $\mathrm{MH}$ during the last half of gestation on bone structure and volume in the offspring before and after birth.

\section{Materials and Methods}

2.1. Animals. All procedures were approved by the Animal Ethics Committees at the University of South Australia (IMVS) and the University of Adelaide. IMVS tricoloured guinea pigs were individually housed at $18-22^{\circ} \mathrm{C}$ and in a 12/12 light cycle. All animals were fed standard laboratory rabbit/guinea pig chow (Laucke Mills, Daveyston, Australia) with ad libitum access to water supplemented with $0.5 \mathrm{~g} / \mathrm{L}$ Vitamin C. Breeding females (sows) were weighed and given a known weight of food three times weekly. The remaining food was weighed to determine food intake per gram of body weight. After 4-6 weeks of controlled feeding, breeding females were placed with a male for $24 \mathrm{~h}$ and were mated. Females in oestrus were placed with a male overnight and pregnancy was detected by the presence of a vaginal copulatory plug the following morning and a failure to return to oestrus in the subsequent cycle $[22,23]$.

2.2. Experimental Protocol and Specimens. At $35 \mathrm{~d}$ gestation, pregnant sows were randomly assigned to control or $\mathrm{MH}$ groups. Sows assigned to $\mathrm{MH}$ were housed in $12 \%$ oxygen (half of normal \% of oxygen in air [24]) with ad libitum access to food. For fetal studies $(n=5)$, MH continued until sows and fetuses were humanly killed at $62 \mathrm{~d}$ gestation (term, $69 \mathrm{~d})$ with an overdose of sodium pentobarbitone $(325 \mathrm{mg} / \mathrm{mL}$ pentobarbitone sodium; Virbac Pty Ltd., Peakhurst, Australia). For postnatal studies $(n=5)$, MH continued until $65 \mathrm{~d}$ gestation, whereupon pregnant sows were returned to normoxia ( $21 \%$ oxygen in air), to ensure pups were born into normoxia. All sows and pups were exposed to normoxia with ad libitum access to food during lactation and postweaning. Pups were weaned at $28 \mathrm{~d}$ and subsequently housed in same sex pairs until humanely killed at 120d (adulthood [25]) with a sodium pentobarbitone overdose as above.

The left tibias from each fetus and pup were collected, fixed in 10\% formalin, and decalcified in Immunocal solution (Decal Corporation, Tallman, NY) for $14 \mathrm{~d}$ at $4^{\circ} \mathrm{C}$ prior to being bisected longitudinally and processing for paraffin wax embedding and sectioning $(4 \mu \mathrm{m})$. The right tibia was used to collect growth plate and metaphysis bone samples that were frozen in liquid nitrogen and stored at $-80^{\circ} \mathrm{C}$ until being used for RNA extraction and gene expression analysis. Bone marrow cells were collected from the fetal femurs by flushing with basal cell culture medium as described [26].

\subsection{Histomorphometric Analysis of Growth Plate and Meta-} physeal Bone. To examine treatment effects on bone growth, bone structure, and volume, H\&E-stained proximal tibial sections were used for basic histomorphometric measurements including growth plate thickness, primary spongiosa height, and secondary trabecular bone volume (BV/TV) as previously described $[27,28]$ and total adipocyte counts (number/ $\mathrm{mm}^{2}$ bone marrow area) in lower secondary spongiosa as previously described [26].

2.4. Colony Forming Unit-Fibroblast Assay. To determine treatment effects on the size of the osteoprogenitor cell pool, a colony forming unit-fibroblast (CFU-f) assay and alkaline phosphatase (ALP, an osteoprogenitor cell marker) staining were performed with bone marrow cells obtained from fetal femurs as described [29]. Briefly, isolated bone marrow cells were plated at $2 \times 10^{6}$ mononuclear cells (MNCs)/well in 6-well tissue culture dishes with complete medium $(\alpha$ MEM supplemented with $10 \% \mathrm{FBS}, 50 \mu \mathrm{g} / \mathrm{mL}$ Pen/Strep, $15 \mathrm{mM}$ HEPES, and $100 \mu \mathrm{M}$ L-ascorbic acid-2-phosphate). Cells were cultured for $14 \mathrm{~d}$ with media changed every $3 \mathrm{~d}$. At the end of culture, cells were fixed with $4 \%$ paraformaldehyde and stained for ALP using a kit (Roche Biochemicals, Sydney, Australia). The number of positive colonies (osteoprogenitor cell pool in the bone marrow) was expressed as CFU-f ALP $^{+}$ colonies per $2 \times 10^{6}$ MNCs.

2.5. Real-Time Reverse Transcriptase Polymerase Chain Reaction (RT-PCR). Frozen growth plate and metaphyseal bone specimens were ground to fine powder with liquid nitrogen using a mortar and pestle, and total RNA was extracted using TRI reagent (Sigma, NSW, Australia). To generate the template for PCR amplification, $2 \mu \mathrm{g}$ of metaphyseal RNA was reverse transcribed into cDNA using the high 
TABLE 1: Effects of MH on body weights of fetal guinea pigs at $62 \mathrm{~d}$ gestation and postnatal guinea pigs at day 120 . Values are means $( \pm$ SEM), $n=5$.

\begin{tabular}{lcccc}
\hline \multirow{2}{*}{ Treatment } & \multicolumn{2}{c}{ Fetal Guinea Pig } & \multicolumn{2}{c}{ Post natal Guinea Pig } \\
& Control & Hypoxic & Control & Hypoxic \\
\hline $\begin{array}{l}\text { Body weight, } \\
\text { grams (sem) }\end{array}$ & $84.4(3.5)$ & $66.9^{*}(2.2)$ & $869.2(50.9)$ & $858.4(44.3)$ \\
\hline
\end{tabular}

${ }^{*} P<0.05$ when compared to control.

capacity RNA-to-cDNA kit (Applied Biosystems, Foster City, CA). All PCR primers (Table 2) were designed using guinea pig DNA sequences and NCBI PRIMER BLAST software and supplied by GeneWorks (Adelaide, SA, Australia). For quantitative RT-PCR of genes of interest (Table 2), a realtime PCR reaction of $10 \mu \mathrm{L}$ was set up using SYBR1 Green master mix (Applied Biosystems). For each cDNA sample, quantitative PCR assays were run on a 7500 Fast Real-Time PCR System (Applied Biosystems) in duplicate. From the amplification curves, relative expression was calculated using the comparative $2^{-\Delta \Delta C T}$ method, with cyclophilin A serving as the endogenous control as described [26].

2.6. Statistical Analysis. Data are presented as means \pm SEM and were analysed using an unpaired Students' $t$-test and were nested for litter using STATA10 (StataCorp, TX, USA). $P<$ 0.05 was considered significant.

\section{Results}

3.1. MH Decreased Offspring Body Weight. $\mathrm{MH}$ resulted in reduced fetal body weight at $62 \mathrm{~d}$ gestation compared to fetuses from control mothers $(P<0.05$; Table 1$)$. However, by $120 \mathrm{~d}$ after birth, there were no differences in body weight between treatment groups.

3.2. MH Did Not Change Growth Plate Thickness. Histomorphometric measurements demonstrated that $\mathrm{MH}$ did not alter tibial growth plate total thickness in either fetal or postnatal offspring compared to controls (Figures 1(a)-1(d), $P>0.05)$. There was no effect of $\mathrm{MH}$ on zonal heights of the growth plate in either the fetal or postnatal tibial bone (Figures 1(c) and 1(d)).

3.3. Gene Expression of Chondrocyte Maturation Markers. The mRNA expression of the key angiogenic growth factor, VEGF, was significantly higher in the growth plate of postnatal offspring exposed to $\mathrm{MH}$ compared to controls (Figure 2(a)). However, there were no differences in the mRNA level of hypoxia-induced factor (HIF-1 $\alpha$ ) between offspring from the $\mathrm{MH}$ and control groups (Figure 2(b)). $\mathrm{MH}$ did not affect levels of mRNA expression of collagen type X (Col10) and matrix metalloprotease-9 (MMP-9), both involved in the maturation of the growth plate cartilage and its bone conversion (Figures 2(c) and 2(d)).

3.4. MH Did Not Change Primary Spongiosa Height of Metaphysis. To examine the effect of $\mathrm{MH}$ on endochondral bone formation, heights of primary spongiosa (newly derived from calcified growth plate cartilage) were measured (Figures 3(a) and 3(b)). MH did not affect the primary spongiosa height of fetal (Figure 3(c)) or postnatal offspring compared to controls (Figure 3(d); $P>0.05$ ).

3.5. Effects of MH on Bone and Bone Marrow Fat Volumes. Metaphyseal trabecular bone volume was analysed in the secondary spongiosa, which is composed of enlarged mineralized bony trabeculae modelled or remodelled from the primary spongiosa. There were no significant differences in bone volume (BV/TV \%) in fetal (Figure 4(a)) or postnatal (Figure 4(c)) offspring of $\mathrm{MH}$ compared to control mothers. When the bone volume was adjusted for body weight (bone volume/body weight), the relative bone volume was higher in $\mathrm{MH}$ compared to control fetuses (Figure 4(b); $P<0.05$ ), but not postnatal offspring (Figure 4(d)).

There were no adipocytes in the bone marrow in fetal guinea pigs (Figure 5(a)). There was no effect of $\mathrm{MH}$ on marrow adiposity in postnatal offspring of $\mathrm{MH}$ compared to control mothers (Figures 5(b), 5(c), and 5(d)).

3.6. MH Did Not Change Osteogenesis but Increased Adipogenesis-Related Gene Expression. Bone sialoprotein (BSP) gene expression in the metaphysis of postnatal offspring was not affected by $\mathrm{MH}$ (Figure 6(a)). However, $\mathrm{MH}$ offspring had a lower level of collagen-1 (Cola1) mRNA expression compared to control offspring after birth $(P<0.05$; Figure 6(b)). While there were no significant changes in mRNA expression of the adipogenic transcription factor, peroxisome proliferator-activated receptor gamma (PPAR $\gamma$; Figure 6(c)), $\mathrm{MH}$ induced an increase in mRNA expression of fatty acid binding protein 4 (FABP4) in the postnatal offspring (Figure 6(d)).

3.7. MH Did Not Change the Size of the Bone Marrow Osteoprogenitor Cell Pool. CFU-f assay and ALP staining were carried out with bone marrow samples from the fetal guinea pigs to examine the osteoprogenitor cell pool in the bone marrow (Figure 7). There were no significant differences in the osteoprogenitor pool size in fetal offspring of mothers from both groups.

\section{Discussion}

One of the main consequences of fetal growth restriction is low birth weights with low bone mass [30, 31]. Population studies have demonstrated that there are associations between weight at 1 year and adult bone mineral contents at lumbar spine and femoral neck as well as adult bone mass $[19,32-34]$. There is also evidence that fetal growth restriction results in an increased risk of osteoporotic fracture [18, 35], suggesting that the lack of nutrients early in life may compromise adult skeleton. The present study has shown that $\mathrm{MH}$ caused a significant reduction in fetal weight. MH did not change the growth plate thickness, despite increased mRNA expression of VEGF in postnatal offspring. Histological and gene expression studies suggest that $\mathrm{MH}$ also reduced bone 
TABLE 2: Primer pairs used in this study.

\begin{tabular}{lcc}
\hline Gene & Forward primer & Reverse primer \\
\hline Cyclophilin A & ATCTGCACTGCCAAGACTGA & TGGTGATCTTCTTGCTGGTC \\
MMP-9 & AGCCCTGCGCGTTTCCCTTC & CCTGGCGACCCTCGGTGGTA \\
ColX & TCGGGCCGCCAGGTATTCCA & AGACCCGGCCTTTGGCCTG \\
HIF1-a & GGGCCGGCTCCCCTACTGTC & CACCGTGCAGGTCCCACCCC \\
PPAR $\gamma-1$ & TAGAGCCTGCATCGCCCCCA & ACACACGCGGCACTCGATGG \\
FABP 4 & TGGCATGGCCAAACCCAGCC & TGCGGTGACTTCATCGAATTCCTGG \\
BSP & CACCACAGCAGGCGCTACCC & GTTCCCGGGTGGGAGGGTGT \\
Colal & CCGGTCCTGCTGGTCCTGCT & GCCTTGTCACCACGGGGACCT \\
\hline
\end{tabular}

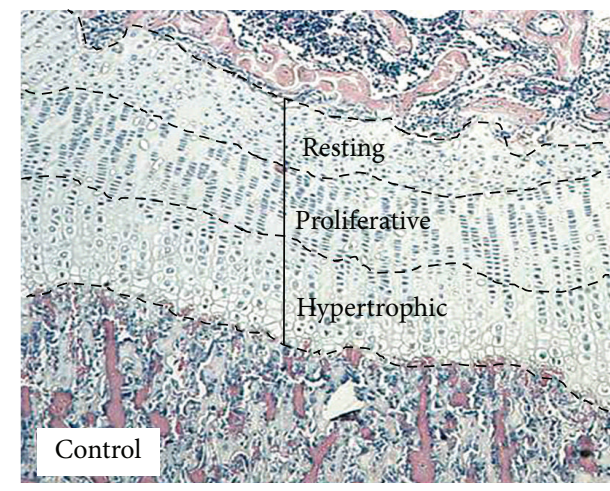

(a)

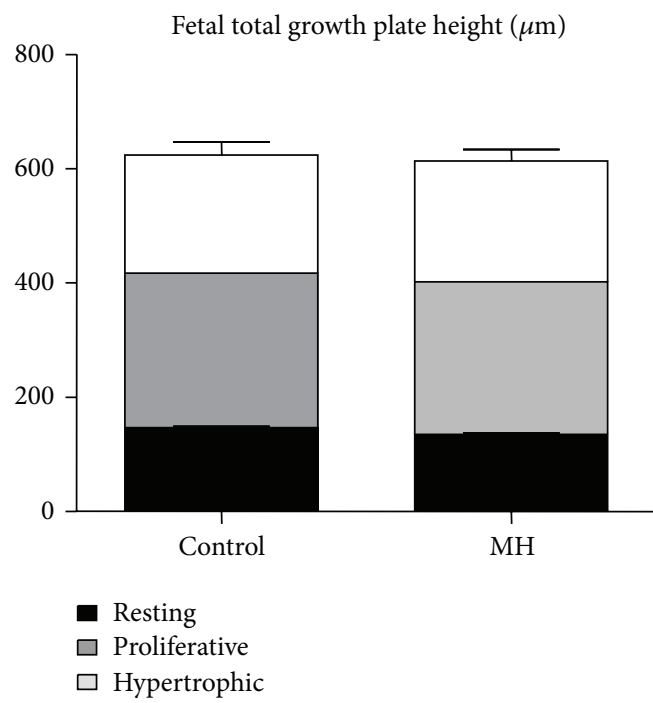

(c)

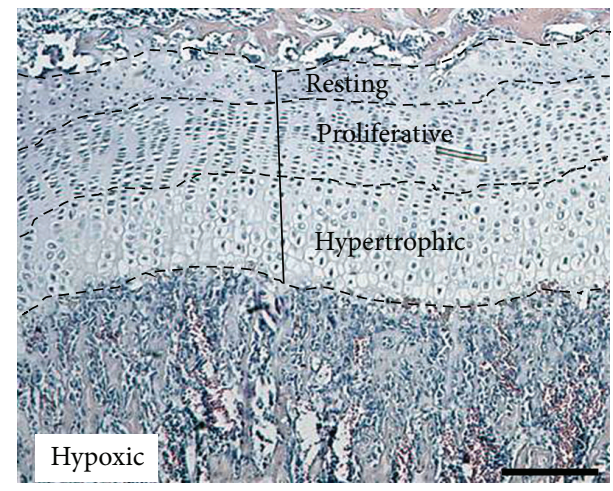

(b)

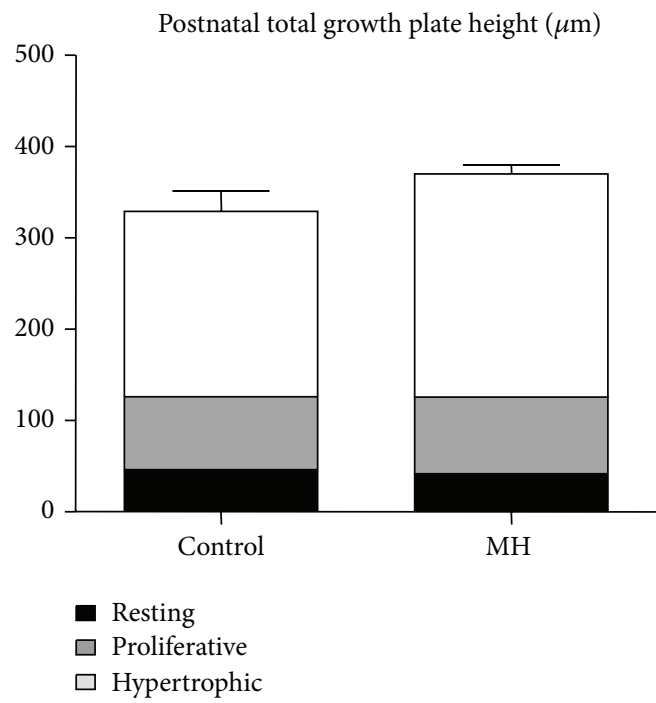

(d)

FIGURE 1: Effects of MH on total thickness and zonal heights in the growth plate of offspring. H\&E-stained tibial sections (showing growth plate height) of 120d postnatal guinea pigs from a control (a) and a hypoxic (b) mother, respectively. The dashed lines in (a) and (b) arbitrarily separate the three individual growth plate zones. (c) Total growth plate thickness and zonal heights (resting, black bar; proliferative, grey bar; hypertrophic, white bar) of 62d gestation fetal guinea pigs from control and hypoxia-treated mothers. (d) Total growth plate thickness and zonal heights of 120d postnatal guinea pigs from control and hypoxia-treated mothers $(n=5)$. Scale bar in (a) $=250 \mu \mathrm{m}$ and applies to (b).

formation potential and a potential increase in bone marrow adiposity (increased FABP4 mRNA expression) in postnatal offspring in this model.

4.1. Effects of Maternal Hypoxia on Histology and Gene Expression in the Growth Plate of Postnatal Offspring. $\mathrm{MH}$ caused fetal growth restriction, but offspring weight was accelerated in postnatal life such that by $120 \mathrm{~d}$ of age offspring in the control and $\mathrm{MH}$ group were the same weight. However, MH had no effect on tibial growth plate thickness or primary spongiosa heights, two regions that are mainly responsible for bone lengthening and bone mass accumulation before or after birth. 


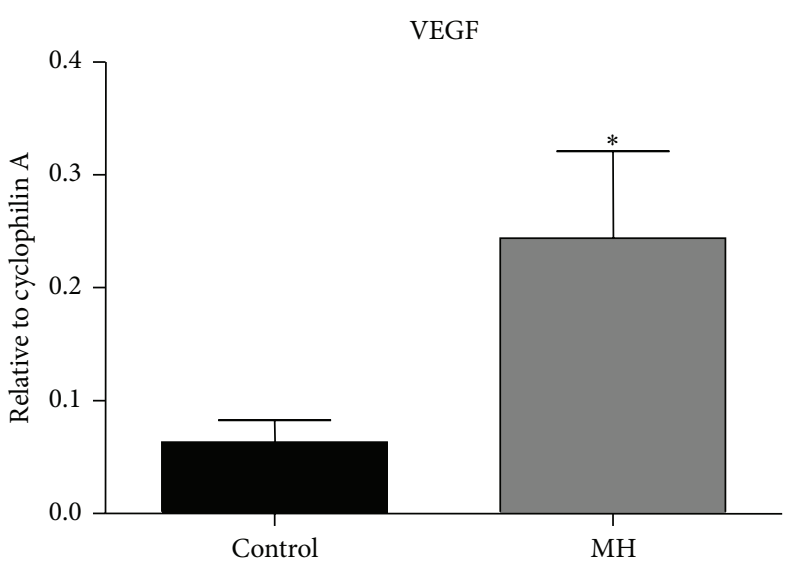

(a)

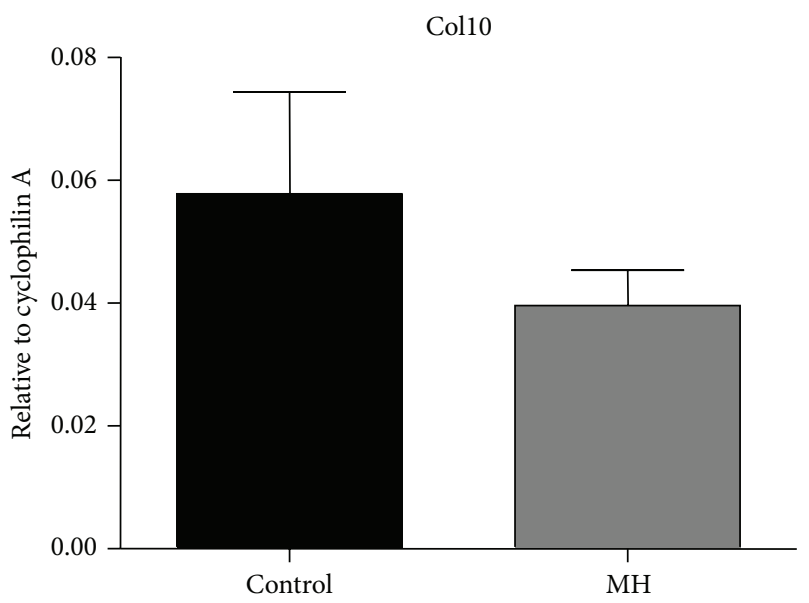

(c)

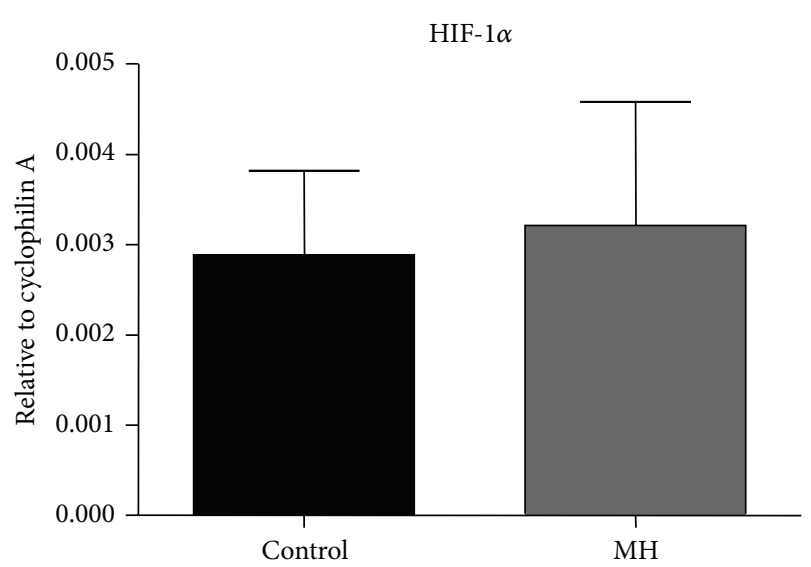

(b)

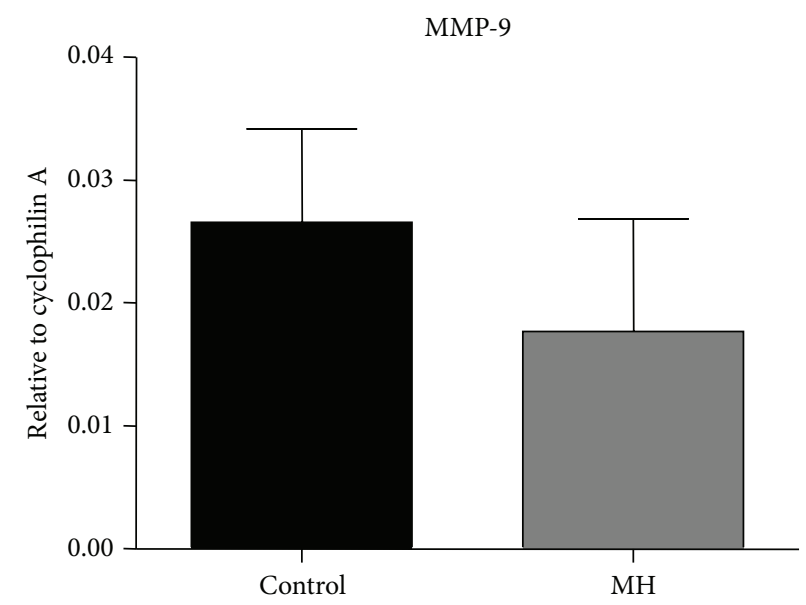

(d)

FIGURE 2: Effects of MH on mRNA expression of genes in growth plate in the postnatal offspring. Quantitative real-time RT-PCR expression data for VEGF (a), HIF-1 $\alpha$ (b), Col10 (c), and MMP-9 (d) are expressed as relative to internal standard cyclophilin A. ${ }^{*} P<0.05$ when compared to control.

There was no change in HIF- $1 \alpha$ mRNA expression in $\mathrm{MH}$ postnatal offspring. There were, however, changes in the expression of some but not all genes that are regulated by HIF-1 $\alpha$. Interestingly, there was a significant elevation in the expression of VEGF in MH postnatal offspring. VEGF is induced by the hypoxia-mediated control of gene expression (particularly HIFs) $[36,37]$ and induces angiogenesis. Our finding of increased VEGF expression is consistent with a previous study where hypoxia increased VEGF production in osteoblasts [38, 39]. HIF-mediated functions assure the differentiation of progenitor cells when the cells are exposed to hypoxic conditions during chondrogenic or osteogenic differentiation in embryo development [40]. It has been shown that placental insufficiency can result in nonphysiological hypoxia, and it appears that timing and extent of the deficiency determine the type of developmental process that is disturbed [41]. In the current study, levels of expression of HIF-1 $\alpha$ in the growth plate of the postnatal offspring of hypoxic mothers remained unchanged, suggesting that the extent of hypoxia did not cause an upregulation of the hypoxic responsive transcription factor. However, further work investigating the protein levels of HIF- $1 \alpha$ is required to understand the mechanism behind the observed increase in VEGF mRNA expression. In addition, $\mathrm{MH}$ did not affect expression of gelatinase or MMP-9 (another downstream target gene of HIF-1 $\alpha$ ) in the growth plate of offspring. Both VEGF and MMP-9 have been shown to play a central role in embryonic bone development and bone remodelling. The lack of effects of MH on HIF-1 $\alpha$ and MMP-9 expression may be related to the extent and duration of $\mathrm{MH}$ of the current study which may not have yielded an adequate in utero stimulus able to alter bone development in the offspring. In addition, the lack of effects could also be due to normalisation of their expression postnatally.

Consistent with the lack of an effect of MH on MMP9 mRNA expression and the height of the growth plate and primary spongiosa, $\mathrm{MH}$ did not change the expression of another hypertrophic cartilage marker Col10 in the growth plate of fetal or postnatal offspring. Thus, while it is difficult to determine whether $\mathrm{MH}$ in the current study may have delayed chondrocyte hypertrophy and endochondral bone development, it is possible that $\mathrm{MH}$ of a greater severity or 


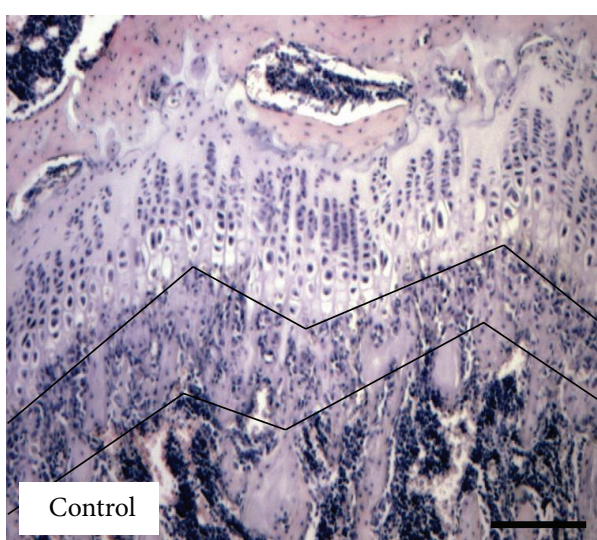

(a)

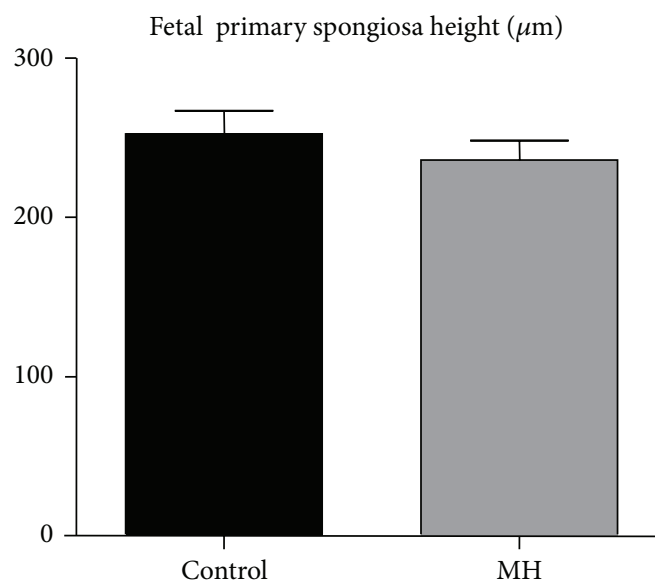

(c)

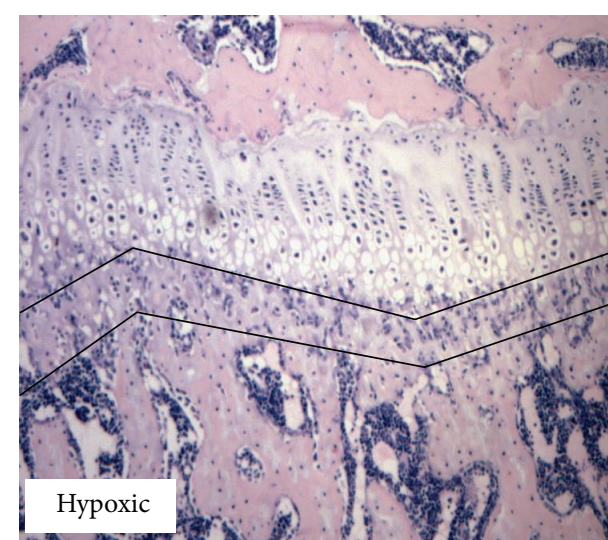

(b)

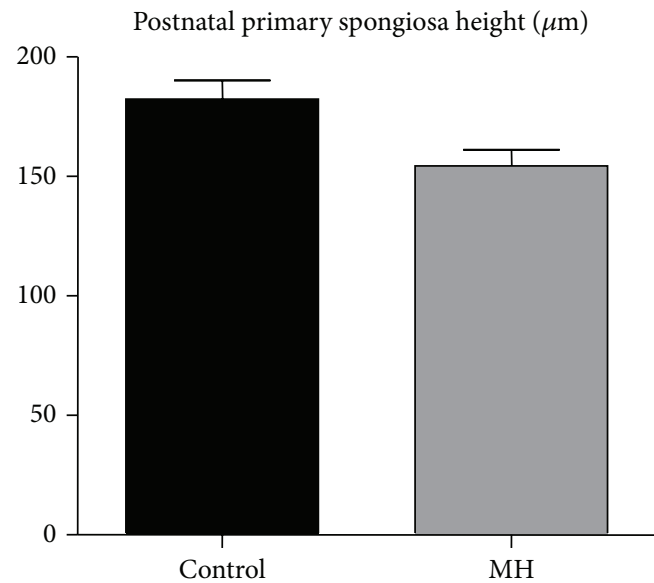

(d)

FIGURE 3: Effects of maternal hypoxia on offspring proximal tibia primary spongiosa height. (a) and (b) H\&E-stained tibial sections (primary spongiosa shown between two tracing lines) of 120d postnatal guinea pigs from a control and a hypoxic mother, respectively. (c) Primary spongiosa height of (c) $62 \mathrm{~d}$ gestation fetal and (d) postnatal $120 \mathrm{~d}$ guinea pigs from control and hypoxia-treated mothers $(n=5)$. Scale bar in (a) $=1 \mathrm{~mm}$ and applies to (b).

a longer duration may have had a significant effect. Although in vitro studies have demonstrated that high oxygen tensions favour the hypertrophic differentiation of chondrogenic cultures or tissues $[42,43]$ associated with a possible increase in the expression of the hypertrophic cartilage marker genes, MMP13, and collage type 10 [44], a possibility for the lack of significant differences in the current model is adaptation, which has been previously shown in rabbit heart [45].

4.2. Effects of Maternal Hypoxia on Bone Structure in the Postnatal Offspring. There was no effect of $\mathrm{MH}$ on trabecular bone histological measurements in the long bones of postnatal offspring, which may further support the importance of the postnatal environment in contributing to the growth and development of the offspring. Some of the negative effects of fetal growth restriction on postnatal health can be rescued by the provision of a normal lactation environment [46], demonstrating that the postnatal environment is also influential in long-term bone health outcome [46]. The variable long-term effects of low birth weight on bone mineral density or hip fracture risk later in life suggest other contributing factors such as physical activity and nutrition may have a more substantial role in determining hip fracture risk [47]. These studies further suggest that bone mass at adulthood rather than at adolescence may be more important in determining the effects of $\mathrm{MH}$ and the onset of osteoporosis.

\subsection{Effects of Maternal Hypoxia in the Bone Marrow Adiposity.} $\mathrm{MH}$ in the current model did not change adipocyte contents or expression of the key adipogenesis-related gene PPAR $\gamma$; there was an increase in the mRNA expression of FABP4 and decrease in the mRNA expression of the bone formation marker Colal (despite a lack of change in bone volume fraction) in the metaphysis bone. These results suggest that although the bone volume fraction may have recovered from the in utero hypoxia as they were placed in normal normoxic environment postnatally, $\mathrm{MH}$ may have caused some permanent damage in the metaphysis that may have consequences later in life. Adipocytes and osteoblasts share a common stromal precursor in the bone marrow [48] and it has been suggested that there is a potential switch in differentiation of bone marrow stromal progenitor cells towards 


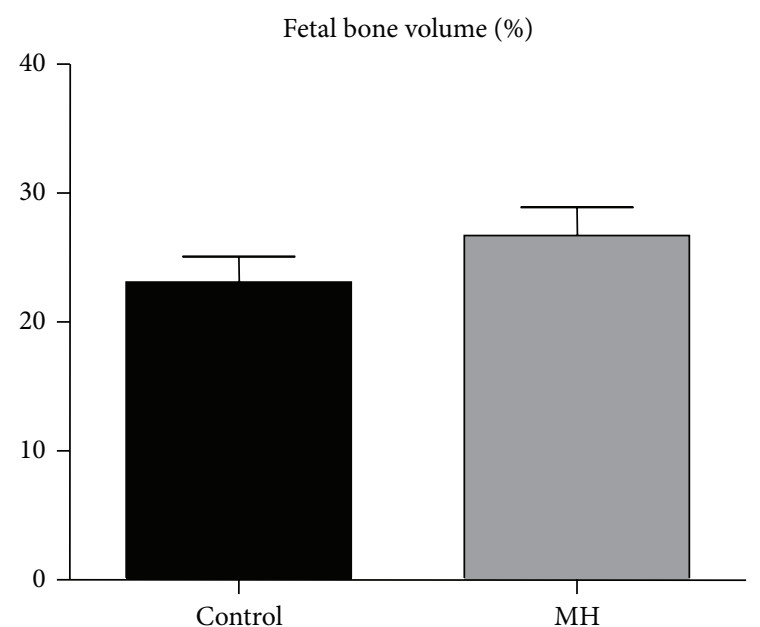

(a)

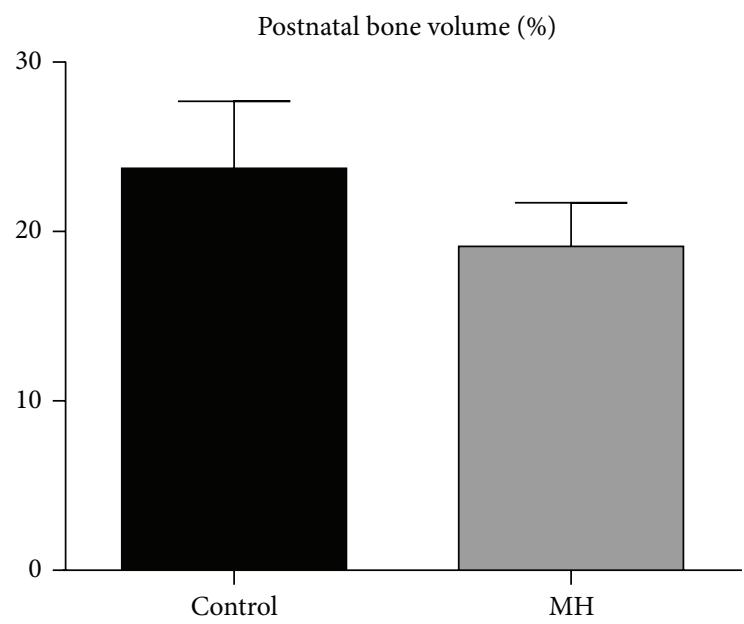

(c)

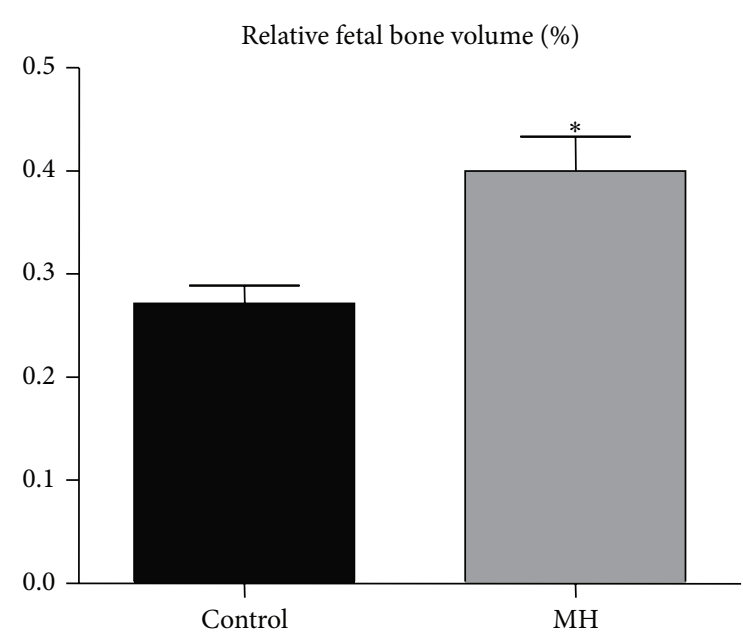

(b)

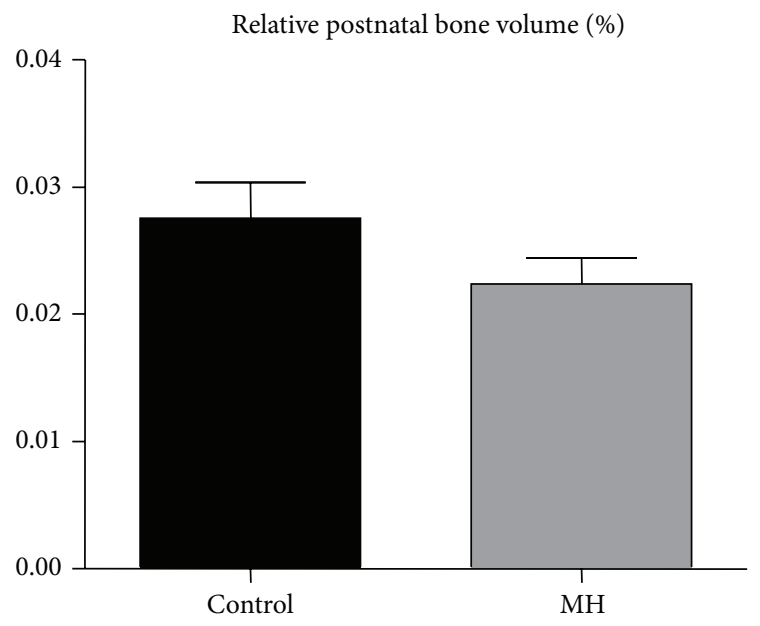

(d)

Figure 4: Effects of MH on tibial trabecular bone volume as measured by histomorphometry (BV/TV, \%). (a) BV/TV of fetal bones from control and hypoxia-treated mothers. (b) Relative BV/TV (adjusted for total body weight) in fetal guinea pigs (\%/g). (c) BV/TV of bones of $120 \mathrm{~d}$ postnatal guinea pigs from control and hypoxia-treated mothers. (d) Relative BV/TV in postnatal guinea pigs (adjusted for total body weight, \%/g). ( $n=5,{ }^{*} P<0.05$ when compared to control).

adipogenesis at the expense of osteogenesis in response to damages/stress [49]. This suggests that this mechanism may be present in the $\mathrm{MH}$ offspring, which is supported by the increase in mRNA expression of the adipogenesis-related gene FABP4 and the reciprocal reduction in the expression of the osteogenesis gene Colal in the bone. Previously, longterm $\mathrm{MH}$ in sheep increased mRNA expression of PPAR $\gamma$ and its coactivator $(\mathrm{PGCl} \alpha) \mathrm{mRNA}$ in perirenal adipose tissue in late gestation [50], suggesting that there is an effect of hypoxia on adipogenesis in both bone marrow and extraosseous adipose tissues. These studies suggest that $\mathrm{MH}$ in the current setting may not be as detrimental to the bone and bone marrow as demonstrated by the lack of effects of $\mathrm{MH}$ on fetal guinea pigs.

4.4. Effects of Maternal Hypoxia on the Size of Fetal Bone Marrow Osteoprogenitor Cell Pool. MH did not change bone histomorphometry in fetal offspring, suggesting that osteogenic differentiation potential of bone marrow progenitor cells $\left(\mathrm{ALP}^{+} \mathrm{CFU}-\mathrm{F}\right.$ colonies formed) was not affected by $\mathrm{MH}$. The effect of $\mathrm{MH}$ on the osteogenic potential in the fetal offspring has not previously been studied. Several in vitro studies have demonstrated a negative effect of hypoxia on cell growth [39, 51] and osteogenic differentiation [21, 51], while others have shown a positive outcome for osteoblastic differentiation [52]. Hypoxia (2\% oxygen) inhibited proliferation and delayed osteoblast differentiation of immature calvarial osteoblast precursors from neonatal rats [53]. In addition, hypoxia inhibited mineralised nodule formation by osteoblasts at both early and late stages of culture, which recovered well when cells were transferred to normal $\mathrm{O}_{2}$ levels after early exposure [53]. However, Salim et al. found difference between $21 \% \mathrm{O}_{2}$ and $2 \% \mathrm{O}_{2}$ conditions on differentiation potential of osteoblasts but diminished osteoblastic differentiation at $0.02 \% \mathrm{O}_{2}$ [21]. These inconsistent studies suggest that 


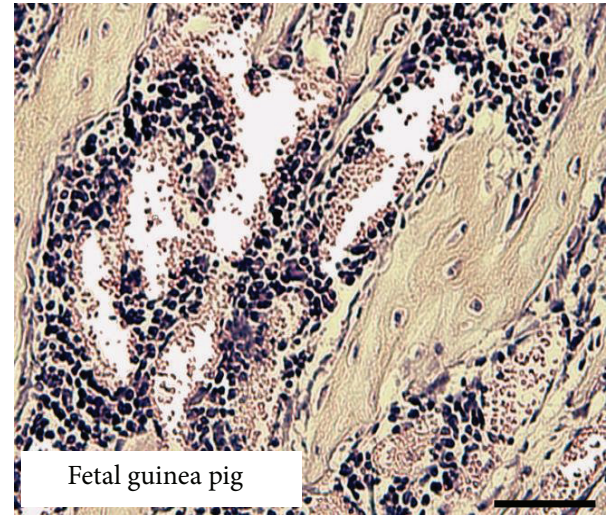

(a)

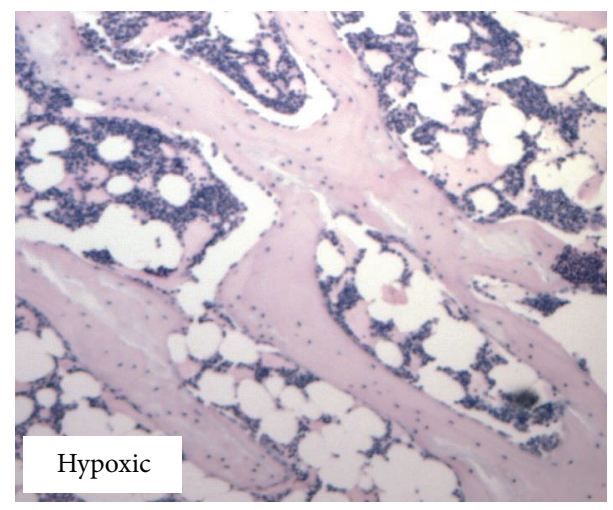

(c)

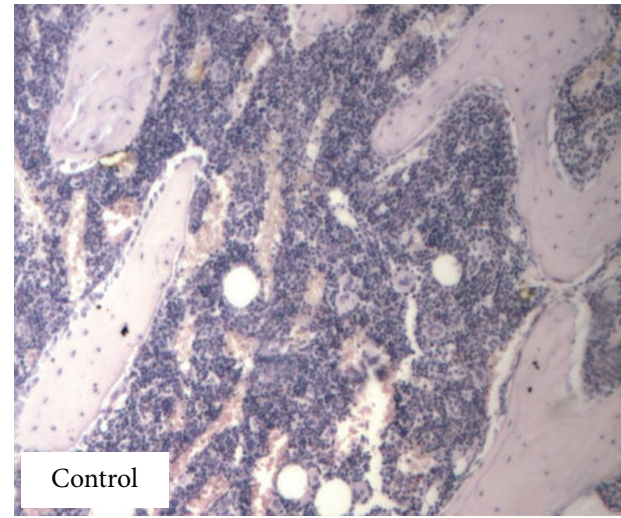

(b)

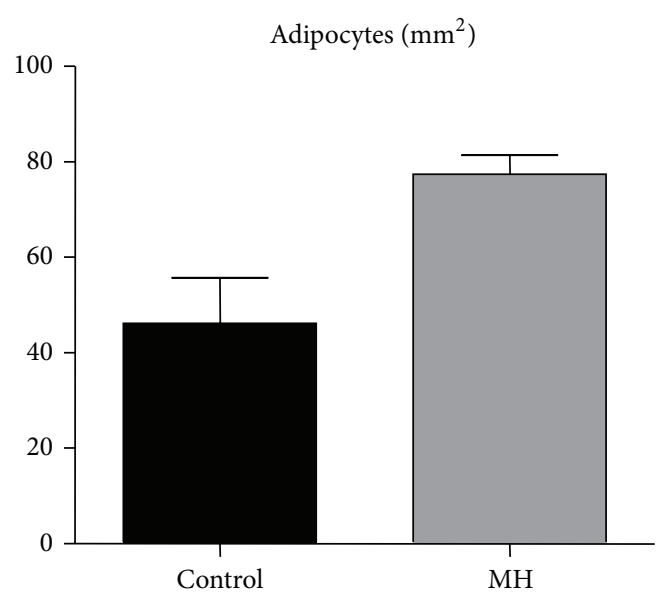

(d)

Figure 5: Effects of MH on numbers of adipocytes in the lower secondary spongiosa of tibial bone. (a) Bone marrow in fetal guinea pigs does not contain adipocytes (a section from a control fetal guinea pig). Bone marrow showing presence of adipocytes in a day 120 postnatal guinea pig from a control (b) and a hypoxic mother (c). (d) Bone marrow adipocytes $/ \mathrm{mm}^{2}$ marrow area from control and hypoxia-treated mothers. $n=5$. Scale bar in (a) $=500 \mu \mathrm{m}$ and applies to (b) and (c).

effects of exposure to hypoxia of mesenchymal stem cells or osteoblastic cells may be time and dose dependent.

In summary, some previous studies have suggested that adverse influences, arising in fetal life or immediately after birth, may have an important effect on later risk of lower bone mass or osteoporotic fracture. We have demonstrated that $\mathrm{MH}$ during pregnancy in this model does not change growth plate and bone structures in offspring before and after birth. However, gene expression studies suggest that MH may have damaged the bone as demonstrated by an upregulation of genes involved in fat formation and a reciprocal downregulation of the genes involved in bone formation despite the lack of obvious changes in bone volume and adipocyte content in the postnatal bone marrow in this model. Further studies investigating the effects of maternal insufficiencies during the different stages of prenatal development and postnatal growth in offspring would increase our understanding of the consequences on offspring bone development and identify the crucial time points whereby changes in growth plate, bone, and bone marrow can be observed. Further investigations should be performed to determine if intrauterine insults can be rescued with postnatal nutritional interventions which may lead to the prevention of adult diseases such as osteoporosis.

\section{Limitations}

The current study has raised many questions which require further investigations. As the current study was limited to only observe the effects of maternal hypoxia at one point after birth, a future study should be carried out using the current model but with different observation time points such as 1 , 3 , and 5 months postnatally. This will further explain the influence of maternal hypoxia on bone development at different stages of skeletal development postnatally. Furthermore, although the bone volume in the current model was found to be not compromised by maternal hypoxia, biomechanical studies looking at the breaking strength of long bones as well as measurements of bone mineral contents (as measured by the ash weight of bone samples) should be employed to fully understand the effects of maternal hypoxia on the bone development in their offspring. Moreover, further studies should be carried out to investigate the proliferation and differentiation potentials of the marrow progenitor cells 


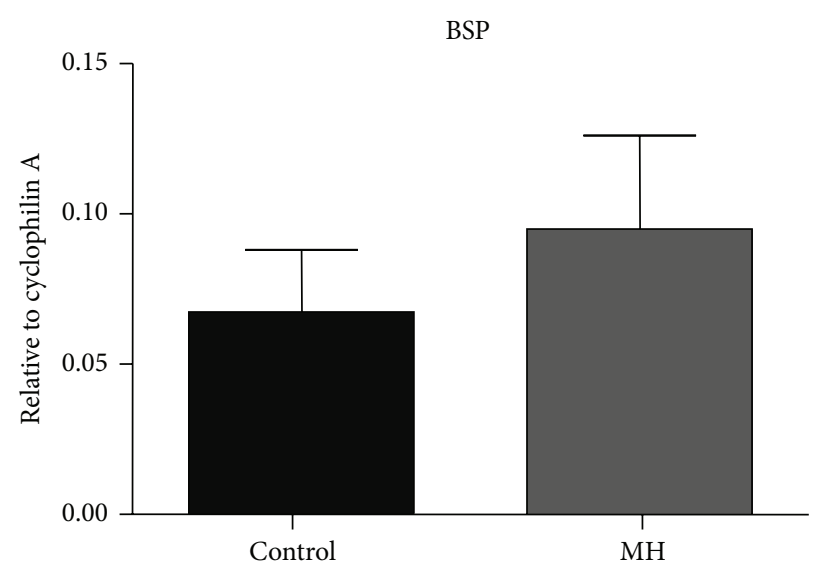

(a)

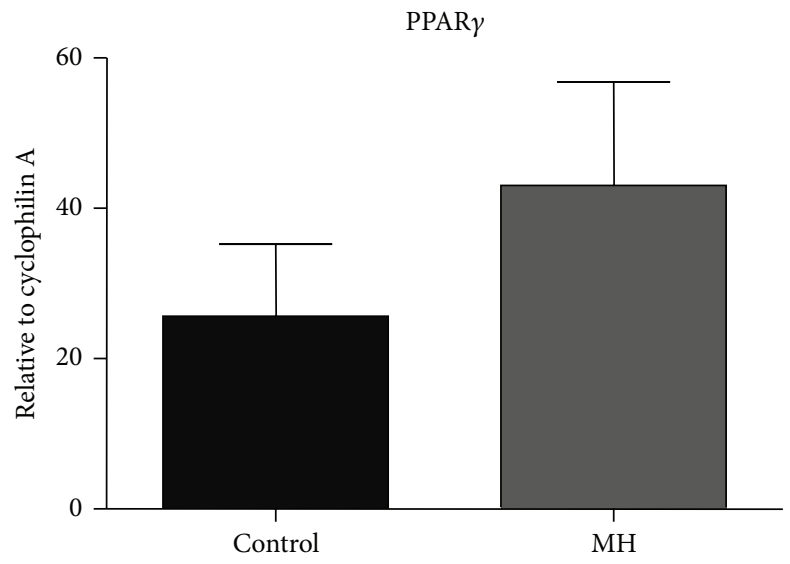

(c)

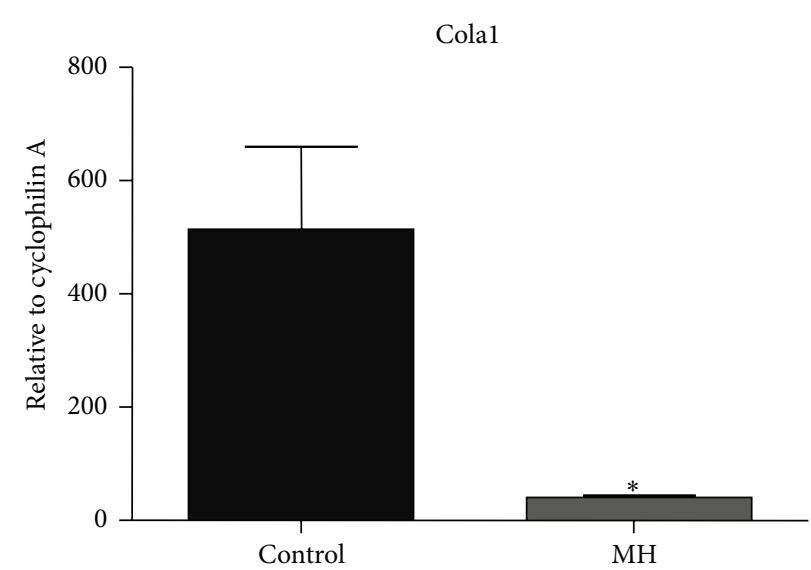

(b)

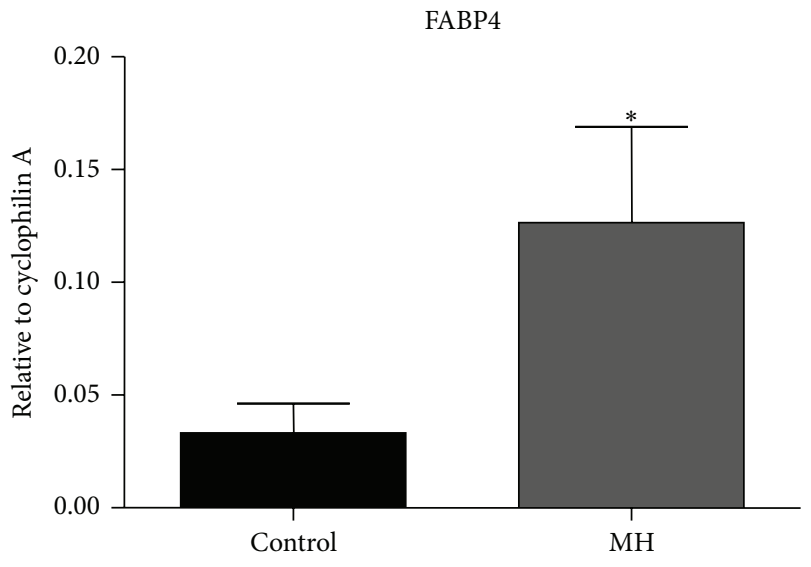

(d)

FIgURE 6: Effects of $\mathrm{MH}$ on mRNA expression of genes in the metaphysis bone of postnatal offspring. Quantitative real-time RT-PCR expression data for BSP (a), Colal (b), PPAR $\gamma(\mathrm{c})$, and FABP4 ((d), $P=0.05)$ are expressed relative to internal standard cyclophilin A. ${ }^{*} P<0.05$ when compared to control $(n=5)$.

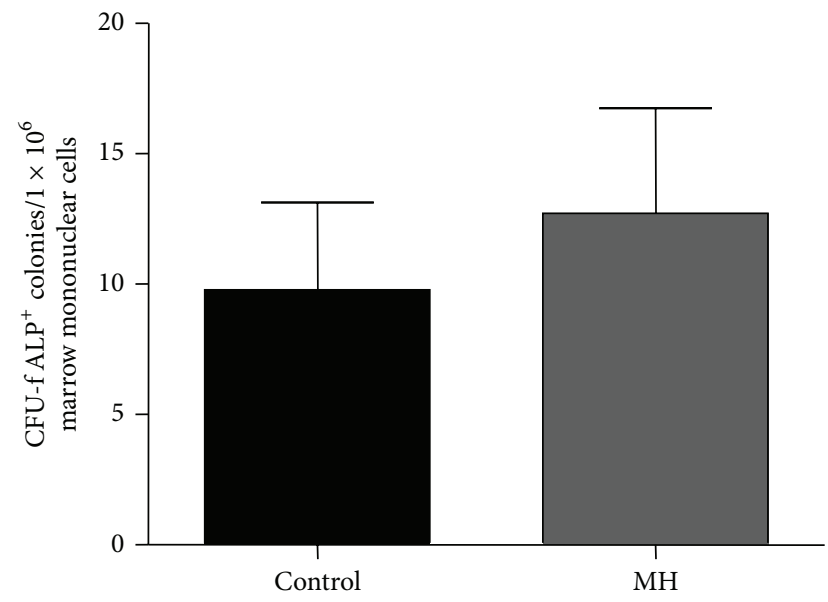

FIGURE 7: Effects of $\mathrm{MH}$ on the osteoprogenitor cell pool in bone marrow of fetal guinea pigs. Data showing the number of CFU$\mathrm{f}$ colonies stained positive for alkaline phosphatase (ALP) in total bone marrow mononuclear cell population (values are means \pm SEM, $n=5)$. isolated from the offspring of hypoxic mothers. In addition, the protein expression of HIF- $1 \alpha$ should also be investigated as it provides a clearer understanding as to whether a hypoxic environment in the bone marrow environment would have been created by maternal hypoxia in bone. Similarly, the sources (or cell types) of expression of key factors particularly RANKL, TNF- $\alpha$ and IL-1, and OCN should be investigated (e.g., by immunohistochemistry) to get more insights into osteoclastogenic and osteogenic potentials of the offspring following maternal hypoxia.
Abbreviations
MH: Maternal hypoxia
BMD: Bone mineral density
HIF-1: Hypoxia-inducible factor-1
VEGF: Vascular endothelial growth factor
Cola1: Type 1 collagen
BV/TV: Trabecular bone volume
CFU-f: Colony forming unit fibroblast 
MNCs: Mononuclear cells

RT-PCR: Real-time reverse transcriptase polymerase chain reaction

Col10: Collagen type X

MMP-9: Matrix metalloprotease 9

$\operatorname{PPAR} \gamma$ : Peroxisome proliferator-activated receptor gamma

FABP4: Fatty acid binding protein 4.

\section{Conflict of Interests}

There is no conflict of interests that could be perceived as prejudicing the impartiality of the research reported.

\section{Authors' Contributions}

Alice M. C. Lee, Janna L. Morrison, and Cory J. Xian conceived and designed the experiments. Alice M. C. Lee, Kimberley J. Botting, Tetyana Shandala, and Cory J. Xian performed the experiments. Alice M. C. Lee, Kimberley J. Botting, Tetyana Shandala, and Cory J. Xian analyzed the data. Alice M. C. Lee, Janna L. Morrison, and Cory J. Xian contributed with reagents/materials/analysis tools. Alice M. C. Lee, Janna L. Morrison, and Cory J. Xian wrote the paper.

\section{Acknowledgments}

The authors thank Melissa Walker, Jayne Skinner, Bang Hoang, Poh Seng Soo, Stacey Dunn, and Kimberley Wang for their assistance with tissue collection. The animal component of this project was funded by the UniSA Research Leadership Program (Janna L. Morrison). Janna L. Morrison was funded by Career Development Awards from the NHF of Australia (CR07A3328) and the NHMRC (511341). Cory J. Xian is funded by NHMRC Senior Research Fellowship. The histological and molecular analysis components of this project were funded in part by grants from Channel-7 Children's Research Foundation of South Australia, Bone Health Foundation, and NHMRC Australia.

\section{References}

[1] C. J. Xian, "Roles of epidermal growth factor family in the regulation of postnatal somatic growth," Endocrine Reviews, vol. 28, no. 3, pp. 284-296, 2007.

[2] B. K. Hall and T. Miyake, "Divide, accumulate, differentiate: cell condensation in skeletal development revisited," International Journal of Developmental Biology, vol. 39, no. 6, pp. 881-893, 1995.

[3] L. Quintana, N. I. Zur Nieden, and C. E. Semino, "Morphogenetic and regulatory mechanisms during developmental chondrogenesis: new paradigms for cartilage tissue engineering," Tissue Engineering B, vol. 15, no. 1, pp. 29-41, 2009.

[4] C. Cooper, N. Harvey, K. Javaid, M. Hanson, and E. Dennison, "Growth and bone development," Nestle Nutrition Workshop Series: Pediatric Program, vol. 61, pp. 53-66, 2008.

[5] H. Ohta, T. Kuroda, Y. Onoe et al., "Familial correlation of bone mineral density, birth data and lifestyle factors among adolescent daughters, mothers and grandmothers," Journal of Bone and Mineral Metabolism, vol. 28, no. 6, pp. 690-695, 2010.

[6] R. El Hage, E. Moussa, A. Hammoud, G. Dandachi, and C. Jacob, "Birth weight is an independent determinant of whole body bone mineral content and bone mineral density in a group of Lebanese adolescent girls," Journal of Bone and Mineral Metabolism, vol. 28, no. 3, pp. 360-363, 2010.

[7] J. Laitinen, K. Kiukaanniemi, J. Heikkinen et al., "Body size from birth to adulthood and bone mineral content and density at 31 years of age: results from the northern Finland 1966 birth cohort study," Osteoporosis International, vol. 16, no. 11, pp. 1417-1424, 2005.

[8] C. J. Hernandez, G. S. Beaupré, and D. R. Carter, "A theoretical analysis of the relative influences of peak BMD, age-related bone loss and menopause on the development of osteoporosis," Osteoporosis International, vol. 14, no. 10, pp. 843-847, 2003.

[9] S. Zhang, L. Rattanatray, J. L. Morrison, L. M. Nicholas, S. Lie, and I. C. McMillen, "Maternal obesity and the early origins of childhood obesity: weighing up the benefits and costs of maternal weight loss in the periconceptional period for the offspring," Experimental Diabetes Research, vol. 2011, Article ID 585749, 10 pages, 2011.

[10] J. L. Morrison, J. A. Duffield, B. S. Muhlhausler, S. Gentili, and I. C. McMillen, "Fetal growth restriction, catch-up growth and the early origins of insulin resistance and visceral obesity," Pediatric Nephrology, vol. 25, no. 4, pp. 669-677, 2010.

[11] I. C. McMillen and J. S. Robinson, "Developmental origins of the metabolic syndrome: prediction, plasticity, and programming," Physiological Reviews, vol. 85, no. 2, pp. 571-633, 2005.

[12] P. Bateson, "Fetal experience and good adult design," International Journal of Epidemiology, vol. 30, no. 5, pp. 928-934, 2001.

[13] J. L. Morrison, "Sheep models of intrauterine growth restriction: fetal adaptations and consequences," Clinical and Experimental Pharmacology and Physiology, vol. 35, no. 7, pp. 730-743, 2008.

[14] P. D. Gluckman, B. H. Breier, M. Oliver, J. Harding, and N. Bassett, "Fetal growth in late gestation-a constrained pattern of growth," Acta Paediatrica Scandinavica, Supplement, vol. 79, no. 367, pp. 105-110, 1990.

[15] L. G. Moor, "Fetal growth restriction and maternal oxygen transport during high altitude pregnancy," High Altitude Medicine and Biology, vol. 4, no. 2, pp. 141-156, 2003.

[16] D. L. Economides and K. H. Nicolaides, "Blood glucose and oxygen tension levels in small-for-gestational-age fetuses," The American Journal of Obstetrics and Gynecology, vol. 160, no. 2, pp. 385-389, 1989.

[17] D. E. Yarbrough, E. Barrett-Connor, and D. J. Morton, "Birth weight as a predictor of adult bone mass in postmenopausal women: the Rancho Bernardo study," Osteoporosis International, vol. 11, no. 7, pp. 626-630, 2000.

[18] C. R. Gale, C. N. Martyn, S. Kellingray, R. Eastell, and C. Cooper, "Intrauterine programming of adult body composition," Journal of Clinical Endocrinology and Metabolism, vol. 86, no. 1, pp. 267272, 2001.

[19] L. Antoniades, A. J. MacGregor, T. Andrew, and T. D. Spector, "Association of birth weight with osteoporosis and osteoarthritis in adult twins," Rheumatology, vol. 42, no. 6, pp. 791-796, 2003.

[20] Ö. Çolak, Ö. Alataş, S. Aydoğdu, and S. Uslu, "The effect of smoking on bone metabolism: maternal and cord blood bone marker levels," Clinical Biochemistry, vol. 35, no. 3, pp. 247-250, 2002. 
[21] A. Salim, R. P. Nacamuli, E. F. Morgan, A. J. Giaccia, and M. T. Longaker, "Transient changes in oxygen tension inhibit osteogenic differentiation and Runx 2 expression in osteoblasts," Journal of Biological Chemistry, vol. 279, no. 38, pp. 4000740016, 2004.

[22] L. T. Nguyen, B. S. Muhlhausler, K. J. Botting, and J. L. Morrison, "Maternal undernutrition alters fat cell size distribution, but not lipogenic gene expression, in the visceral fat of the late gestation guinea pig fetus," Placenta, vol. 31, no. 10, pp. 902-909, 2010.

[23] P. S. Soo, J. Hiscock, K. J. Botting, C. T. Roberts, A. K. Davey, and J. L. Morrison, "Maternal undernutrition reduces Pglycoprotein in guinea pig placenta and developing brain in late gestation," Reproductive Toxicology, vol. 33, no. 3, pp. 374-381, 2012.

[24] L. P. Thompson and Y. Dong, "Chronic hypoxia decreases endothelial nitric oxide synthase protein expression in fetal guinea pig hearts," Journal of the Society for Gynecologic Investigation, vol. 12, no. 6, pp. 388-395, 2005.

[25] K. R. Toyooka, P. B. Connolly, R. J. Handa, and J. A. Resko, "Ontogeny of androgen receptors in fetal guinea pig brain," Biology of Reproduction, vol. 41, no. 2, pp. 204-212, 1989.

[26] K. R. Georgiou, T. J. King, M. A. Scherer, H. Zhou, B. K. Foster, and C. J. Xian, "Attenuated Wnt/ $\beta$-catenin signalling mediates methotrexate chemotherapy-induced bone loss and marrow adiposity in rats," Bone, vol. 50, no. 6, pp. 1223-1233, 2012.

[27] C. J. Xian, J. C. Cool, T. Pyragius, and B. K. Foster, "Damage and recovery of the bone growth mechanism in young rats following 5-fluorouracil acute chemotherapy," Journal of Cellular Biochemistry, vol. 99, no. 6, pp. 1688-1704, 2006.

[28] C. J. Xian, J. C. Cool, M. A. Scherer et al., "Cellular mechanisms for methotrexate chemotherapy-induced bone growth defects," Bone, vol. 41, no. 5, pp. 842-850, 2007.

[29] R. C. Mccarty, S. Gronthos, A. C. Zannettino, B. K. Foster, and C. J. Xian, "Characterisation and developmental potential of ovine bone marrow derived mesenchymal stem cells," Journal of Cellular Physiology, vol. 219, no. 2, pp. 324-333, 2009.

[30] R. Namgung and R. C. Tsang, "Factors affecting newborn bone mineral content: in utero effects on newborn bone mineralization," Proceedings of the Nutrition Society, vol. 59, no. 1, pp. 5563, 2000.

[31] R. Namgung and R. C. Tsang, "Bone in the pregnant mother and newborn at birth," Clinica Chimica Acta, vol. 333, no. 1-2, pp. 1-11, 2003.

[32] C. Cooper, M. Cawley, A. Bhalla et al., "Childhood growth, physical activity, and peak bone mass in women," Journal of Bone and Mineral Research, vol. 10, no. 6, pp. 940-947, 1995.

[33] C. Cooper, C. Fall, P. Egger, R. Hobbs, R. Eastell, and D. Barker, "Growth in infancy and bone mass in later life," Annals of the Rheumatic Diseases, vol. 56, no. 1, pp. 17-21, 1997.

[34] E. M. Dennison, H. E. Syddall, A. A. Sayer, H. J. Gilbody, and C. Cooper, "Birth weight and weight at 1 year are independent determinants of bone mass in the seventh decade: the hertfordshire cohort study," Pediatric Research, vol. 57, no. 4, pp. 582586, 2005.

[35] C. Cooper, M. K. Javaid, P. Taylor, K. Walker-Bone, E. Dennison, and N. Arden, "The fetal origins of osteoporotic fracture," Calcified Tissue International, vol. 70, no. 5, pp. 391-394, 2002.

[36] G. L. Semenza, "Regulation of mammalian $\mathrm{O}_{2}$ homeostasis by hypoxia-inducible factor 1," Annual Review of Cell and Developmental Biology, vol. 15, pp. 551-578, 1999.
[37] A. L. Kung, S. Wang, J. M. Klco, J. Kaelin W.G., and D. M. Livingston, "Suppression of tumor growth through disruption of hypoxia-inducible transcription," Nature Medicine, vol. 6, no. 12, pp. 1335-1340, 2000.

[38] N. Akeno, M. F. Czyzyk-Krzeska, T. S. Gross, and T. L. Clemens, "Hypoxia induces vascular endothelial growth factor gene transcription in human osteoblast-like cells through the hypoxia-inducible factor-2 $\alpha$," Endocrinology, vol. 142, no. 2, pp. 959-962, 2001.

[39] D. S. Steinbrech, B. J. Mehrara, P. B. Saadeh et al., "Hypoxia regulates VEGF expression and cellular proliferation by osteoblasts in vitro," Plastic and Reconstructive Surgery, vol. 104, no. 3, pp. 738-747, 1999.

[40] A. B. Adesida, A. Mulet-Sierra, and N. M. Jomha, "Hypoxia mediated isolation and expansion enhances the chondrogenic capacity of bone marrow mesenchymal stromal cells," Stem Cell Research and Therapy, vol. 3, no. 2, article 9, 2012.

[41] A. L. Fowden, D. A. Giussani, and A. J. Forhead, "Endocrine and metabolic programming during intrauterine development," Early Human Development, vol. 81, no. 9, pp. 723-734, 2005.

[42] M. Hirao, N. Tamai, N. Tsumaki, H. Yoshikawa, and A. Myoui, "Oxygen tension regulates chondrocyte differentiation and function during endochondral ossification," Journal of Biological Chemistry, vol. 281, no. 41, pp. 31079-31092, 2006.

[43] K. Morita, T. Miyamoto, N. Fujita et al., "Reactive oxygen species induce chondrocyte hypertrophy in endochondral ossification," Journal of Experimental Medicine, vol. 204, no. 7, pp. 1613-1623, 2007.

[44] D. Gawlitta, M. H. van Rijen, E. J. Schrijver et al., "Hypoxia impedes hypertrophic chondrogenesis of human multipotent stromal cells," Tissue Engineering A, vol. 18, no. 19-20, pp. 19571966, 2012.

[45] E. J. Baker, L. E. Boerboom, G. N. Olinger, and J. E. Baker, "Tolerance of the developing heart to ischemia: impact of hypoxemia from birth," The American Journal of PhysiologyHeart and Circulatory Physiology, vol. 268, no. 3, part 2, pp. H1165-H1173, 1995.

[46] T. Romano, J. D. Wark, J. A. Owens, and M. E. Wlodek, "Prenatal growth restriction and postnatal growth restriction followed by accelerated growth independently program reduced bone growth and strength," Bone, vol. 45, no. 1, pp. 132-141, 2009.

[47] E. Araldi and E. Schipani, "Hypoxia, HIFs and bone development," Bone, vol. 47, no. 2, pp. 190-196, 2010.

[48] J. N. Beresford, J. H. Bennett, C. Devlin, P. S. Leboy, and M. E. Owen, "Evidence for an inverse relationship between the differentiation of adipocytic and osteogenic cells in rat marrow stromal cell cultures," Journal of Cell Science, vol. 102, no. 2, pp. 341-351, 1992.

[49] K. R. Georgiou, M. A. Scherer, C.-M. Fan et al., "Methotrexate chemotherapy reduces osteogenesis but increases adipogenic potential in the bone marrow," Journal of Cellular Physiology, vol. 227, no. 3, pp. 909-918, 2012.

[50] D. A. Myers, K. Hanson, M. Mlynarczyk, K. M. Kaushal, and C. A. Ducsay, "Long-term hypoxia modulates expression of key genes regulating adipose function in the late-gestation ovine fetus," The American Journal of Physiology-Regulatory Integrative and Comparative Physiology, vol. 294, no. 4, pp. R1312-R1318, 2008.

[51] J. H. Park, B. H. Park, H. K. Kim, T. S. Park, and H. S. Baek, "Hypoxia decreases Runx2/Cbfal expression in human osteoblast-like cells," Molecular and Cellular Endocrinology, vol. 192, no. 1-2, pp. 197-203, 2002. 
[52] S. M. Warren, D. S. Steinbrech, B. J. Mehrara et al., "Hypoxia regulates osteoblast gene expression," Journal of Surgical Research, vol. 99, no. 1, pp. 147-155, 2001.

[53] J. C. Utting, S. P. Robins, A. Brandao-Burch, I. R. Orriss, J. Behar, and T. R. Arnett, "Hypoxia inhibits the growth, differentiation and bone-forming capacity of rat osteoblasts," Experimental Cell Research, vol. 312, no. 10, pp. 1693-1702, 2006. 


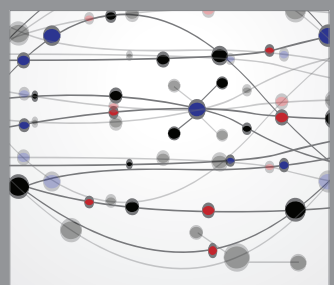

The Scientific World Journal
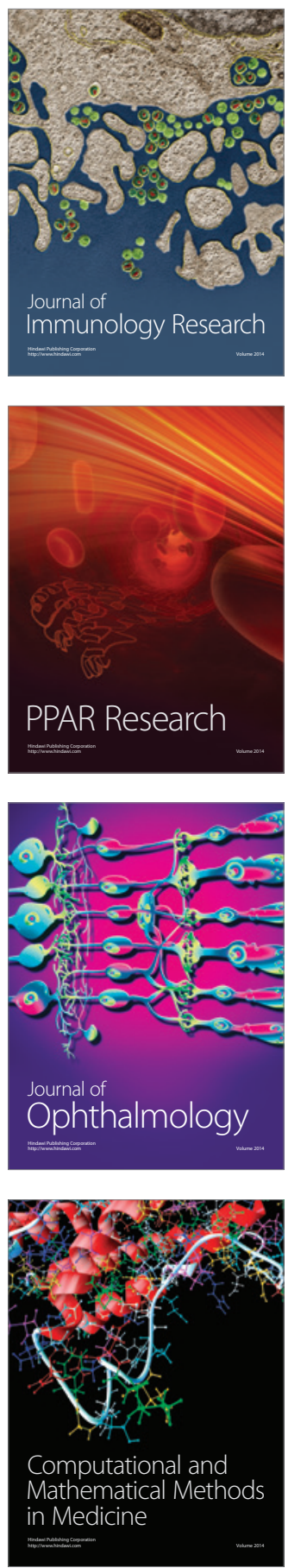

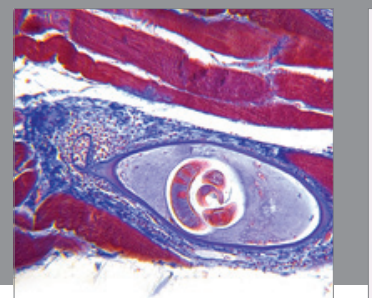

Gastroenterology

Research and Practice
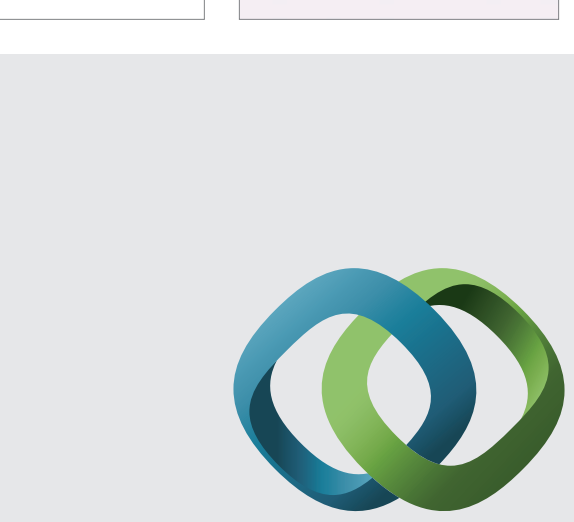

\section{Hindawi}

Submit your manuscripts at

http://www.hindawi.com
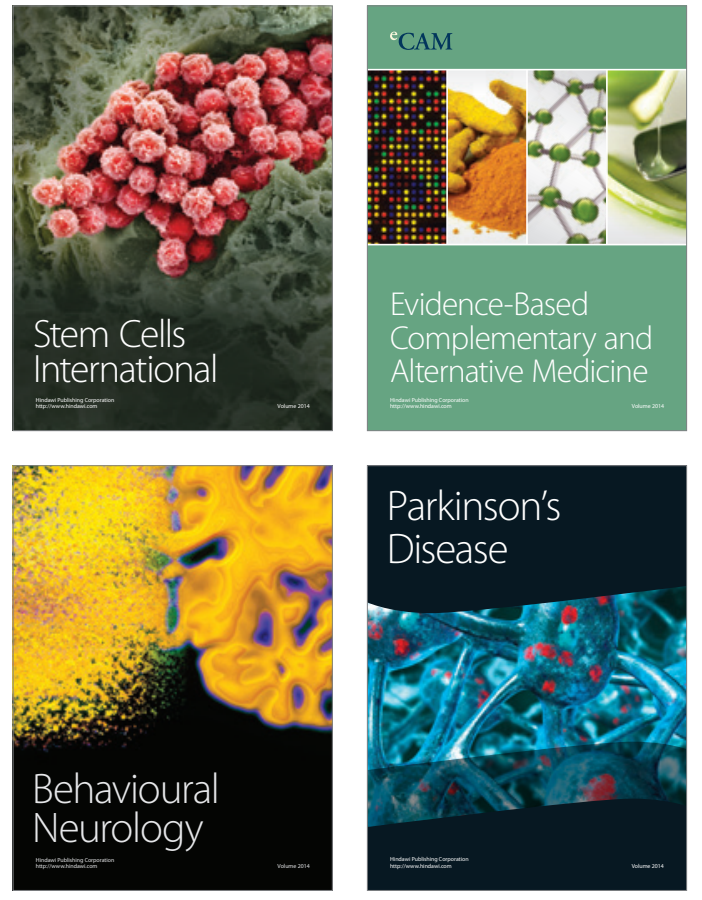
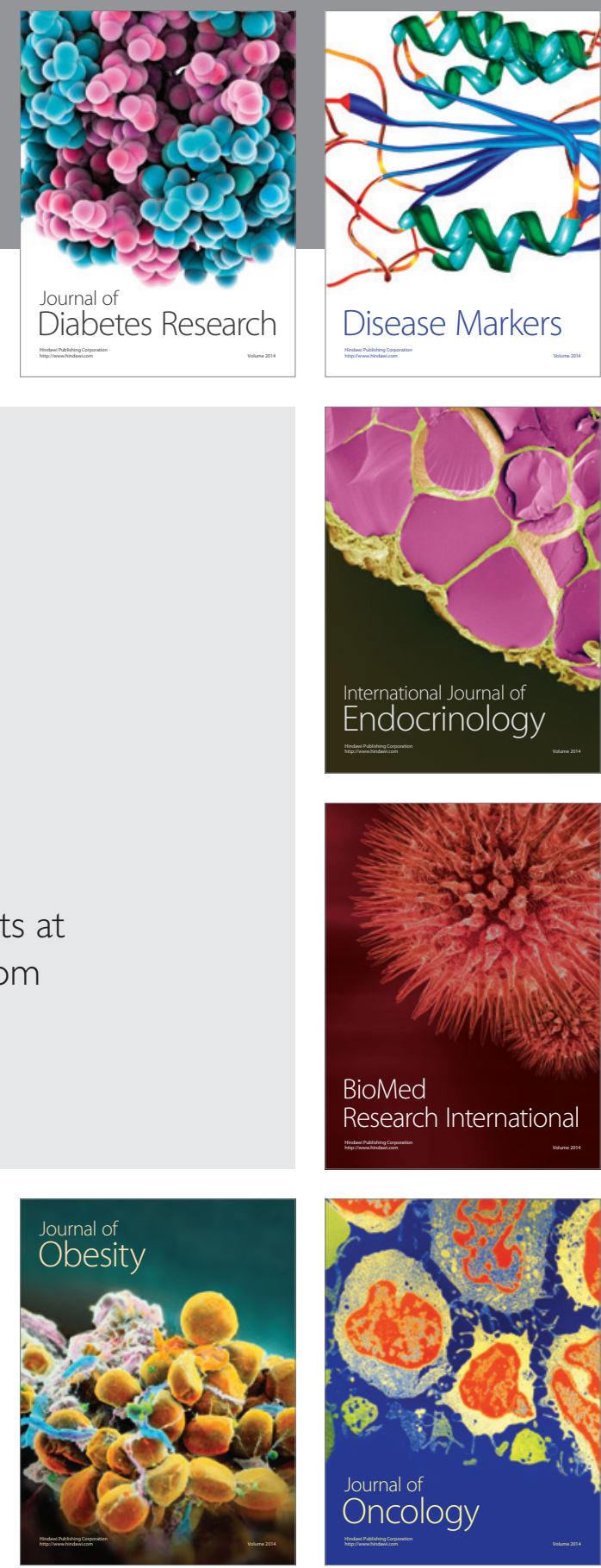

Disease Markers
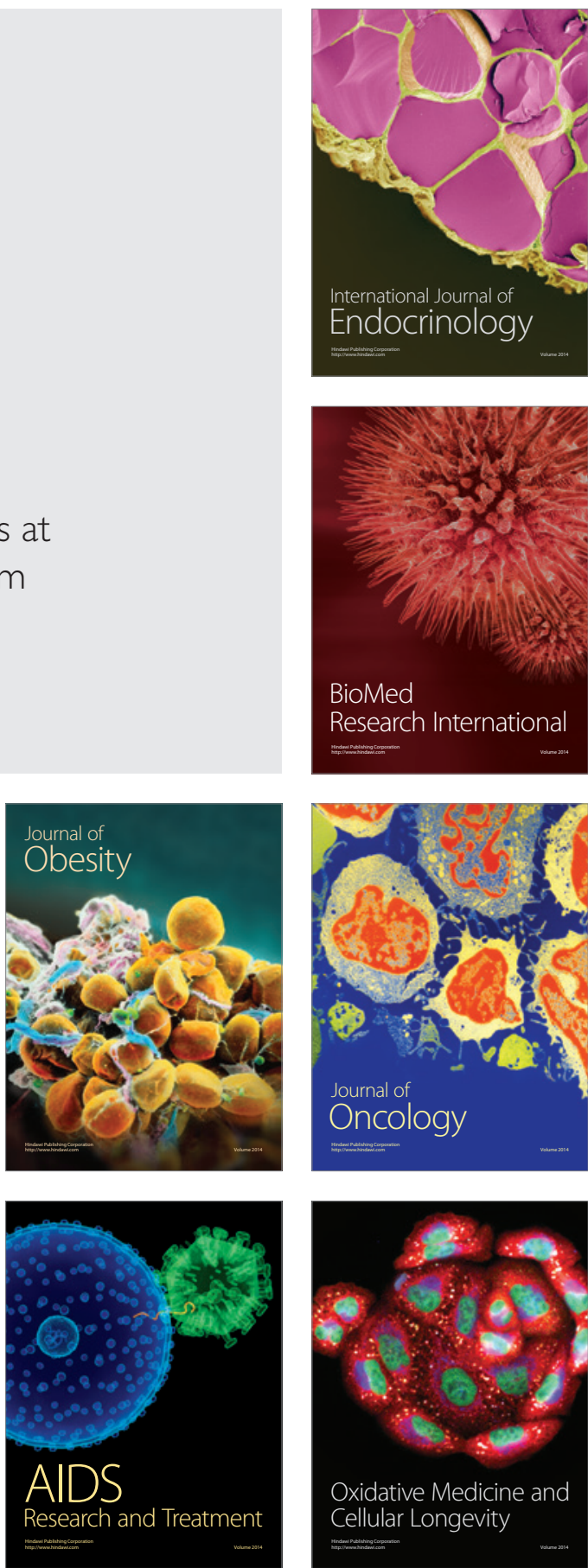